\title{
A Prospective Study to Evaluate the Effectiveness of Prolene Mesh Repair in Incisional Hernia: A Hospital Based Study
}

\author{
Vinod Kumar Jeengar ${ }^{1}$, Rita Verma ${ }^{2}$ \\ ${ }^{1}$ Associate Professor, Department of General Surgery, RVRS Medical College \& Associate Groups of Mahatma Gandhi Hospital, Bhilwara, Rajasthan, India. \\ ${ }^{2}$ Professor, Department of General Surgery, RVRS Medical College \& Associate Groups of Mahatma Gandhi Hospital, Bhilwara, Rajasthan, India.
}

\section{Abstract}

Background: Inguinal hernia is the most common diversity accounting for roughly $75 \%$ of all hernia. The etiology of an inguinal hernia is clearly not understood. The technique of hernia repair is usually based on custom rather than evidence. 4 According to data there is a good observation that open mesh repair is better than suture repair in terms of recurrences. The aim of this study to evaluated the effectiveness of prolene mesh rapair in incisional hernia. Subjects and Methods: A prospective hospital based study done on 30 cases in department of general surgery at RVRS medical college \& associated group of hospitals, Bhilwara, Rajasthan. We randomly assigned 30 patients to suture repair or mesh repair of an incisional hernia. The patients were followed up by local physical examination at 1 month \& 3 months were done as per standard protocol. Factors related to the operation including the surgical technique, presence or absence of seroma, hematoma, infection, dehiscence were recorded. Follow-up of cases was done at 1 month $\& 3$ months after surgery on an outpatient basis for recurrence of hernia. Results: Our study showed that the majority of cases (43.33\%) were seen in 40-49 years of age group. Small (0-5cm) gap size $90 \%$ cases and $10 \%$ cases have medium gap size in our study. Pain present in $26.66 \%$ patients in group A and $20 \%$ in group B at 1 month. The recurrence of hernia was present in $28 \%$ cases in group A and $4 \%$ in group B. It was statistically significant $(\mathrm{P}=0.0488 *)$ at 3 months and the mostly were well built and have $27.27 \%$ wound infection present in these type of patients. Mostly infection occurred in obese patients (40\%). Conclusion: We concluded that restoration with polypropylene mesh is superior to suture repair group with concern to the recurrence of hernia.

Keywords: Inguinal Hernia, Recurrence Rate, Mesh Repair, Suture Repair.

Corresponding Author: Dr. Rita Verma, Professor, Department of General Surgery, RVRS Medical College \& Associate Groups of Mahatma Gandhi Hospital, Bhilwara, Rajasthan, India.

Received: February 2020

Accepted: February 2020

\section{Introduction}

A hernia described as an abnormal protrusion of a viscera, in part or in complete, through a normal or abnormalcongenital or acquired-defect in the wall through the region of the abdominal wall that contains it. The inguinal section is a weakest part of the abdominal wall by the presence of the inguinal canal, the deep inguinal ring and the superficial inguinal ring. All groin hernias appear through the myopectineal orifice of Fruchaud, is bound superiorly by the arching fibers of the transversusabdominis and internal oblique muscles, and inferiorly by the pectineal line. The opening in the lower abdominal wall bounded by the transverse abdomen arch and superior public ramus. ${ }^{[1]}$

Inguinal hernia is the most common diversity accounting for roughly $75 \%$ of all hernia. The etiology of an inguinal hernia is clearly not understood, but it is patent processusvaginalis with increased intra abdominal pressure and relative weakness of posterior inguinal wall are some of the factors related with occurrence of inguinal hernia.

Inguinal mesh hernioplasty is the most common surgical entity performed by general surgeons these days. In the 1990s, mesh hernioplasties became most commonly used, whereas in Finland, the widely used Bassini procedure was almost entirely replaced by tension free Lichtenstein mesh hernioplasty, ${ }^{[2]}$ because Bassini repair was related with high recurrence rate as compared to Lichtenstein mesh repair. ${ }^{[3]}$ The technique of hernia repair is usually based on custom rather than evidence. ${ }^{[4]}$ According to data there is a good observation that open mesh repair is better than suture repair in terms of recurrences. And also an insufficient data to reveal as which type of mesh or which position of mesh (onlay- or sublay) should be used. ${ }^{[5]}$ The aim of this study to evaluated the effectiveness of prolene mesh rapair in incisional hernia.

\section{Subjects and Methods}

A prospective hospital based study done on 30 cases in department of general surgery at RVRS medical college \& associated group of hospitals, Bhilwara, Rajasthan. We randomly assigned 30 patients to suture repair or mesh repair of an incisional hernia. The patients were followed up by local physical examination at 1 month \& 3 months were 
done as per standard protocol. Factors related to the operation including the surgical technique, presence or absence of seroma, hematoma, infection, dehiscence were recorded. Follow-up of cases was done at 1 month \& 3 months after surgery on an outpatient basis for recurrence of hernia.

\section{Inclusion Criteria}

- Age between 10-70 years

- Patients with incisional hernia post laparotomy

\section{Exclusion Criteria}

- Laparoscopic incision site hernia will be excluded

- Pregnant females with incisional hernia

\section{Statistical Analysis}

The values obtained were entered in excel sheet and then appropriate statistical tests were applied to obtain the outcome using the SPSS version 16 software.

\section{Results}

Table 1: Age wise distribution of cases
\begin{tabular}{|l|l|l|}
\hline Age distribution (yrs) & No. of patients & $\%$ \\
\hline $20-29$ & 1 & $3.33 \%$ \\
\hline $30-39$ & 2 & $6.66 \%$ \\
\hline $40-49$ & 13 & $43.33 \%$ \\
\hline $50-59$ & 8 & $26.66 \%$ \\
\hline $60-69$ & 6 & $20 \%$ \\
\hline Total & 30 & $100 \%$ \\
\hline
\end{tabular}

\begin{tabular}{l}
\hline Table 2: Gap size \\
\begin{tabular}{|l|l|l|}
\hline GAP SIZE $(\mathbf{C M})$ & No. of patients & $\%$ \\
\hline $0-5$ (Small) & 27 & $90 \%$ \\
\hline $5-10$ (Medium) & 3 & $10 \%$ \\
\hline Grand Total & 30 & $100 \%$ \\
\hline
\end{tabular}
\end{tabular}

\begin{tabular}{l|l|l|l|l|}
\hline Table 3: Follow-up at 1 month \\
\hline $\begin{array}{l}\text { Follow } \\
\begin{array}{l}\text { Up of 1 } \\
\text { month }\end{array}\end{array}$ & Group A (Suture repair) & \multicolumn{2}{|l|}{ Group B (Mesh repair) } \\
\cline { 2 - 5 } & No. patients & $\%$ & No. of patients & $\%$ \\
\hline Normal & 11 & $73.33 \%$ & 8 & $53.33 \%$ \\
\hline Pain & 4 & $26.66 \%$ & 3 & $20 \%$ \\
\hline $\begin{array}{l}\text { Sensation } \\
\text { of foreign } \\
\text { body }\end{array}$ & 0 & $0 \%$ & 4 & $26.66 \%$ \\
\hline Grand total & 15 & 100 & 15 & 100 \\
\hline
\end{tabular}

Table 4: Follow-up at 3 month

\begin{tabular}{|l|l|l|l|l|}
\hline \multirow{2}{*}{$\begin{array}{l}\text { Follow } \\
\text { Up of 3 } \\
\text { months }\end{array}$} & \multicolumn{2}{|c|}{ Group A (Suture repair) } & \multicolumn{2}{|c|}{ Group B (Mesh repair) } \\
\cline { 2 - 5 } & No. of patients & $\%$ & No. of patients & \% \\
\hline Normal & 11 & $73.33 \%$ & 14 & $93.33 \%$ \\
\hline Recurrence & 4 & $26.66 \%$ & 1 & $6.66 \%$ \\
\hline Grand total & 15 & 100 & 25 & 100 \\
\hline
\end{tabular}

Chi-square test, 1 degree of freedom, $\mathrm{P}=0.0488^{*}$

Table 5: Correlation between obesity and wound infection

\begin{tabular}{|l|l|l|l|}
\hline Health & No of Patients & Wound infection & \% \\
\hline Obese & 5 & 2 & 40 \\
\hline Well Built & 22 & 6 & 27.27 \\
\hline Poorly Built & 3 & 1 & 33.33 \\
\hline
\end{tabular}

Our study showed that the majority of cases (43.33\%) were seen in 40-49 years of age group [Table 1]. Small $(0-5 \mathrm{~cm})$ gap size $90 \%$ cases and $10 \%$ cases have medium gap size in our study [Table 2]. Pain present in $26.66 \%$ patients in group A and $20 \%$ in group B at 1 month [Table 3]. The recurrence of hernia was present in $28 \%$ cases in group A and $4 \%$ in group B. It was statistically significant $\left(\mathrm{P}=0.0488^{*}\right)$ at 3 months and the mostly were well built and have $27.27 \%$ wound infection present in these type of patients. Mostly infection occurred in obese patients $(40 \%)$ [Table 4 \& 5].

\section{Discussion}

In our study the mean age of presentation was 47.6 years (range 20-68 years) and female to male ratio was 1.32:1. As per the Maingot's studies, mean age was around 45 years. ${ }^{[6]}$ Another study done by Bhutia WT et al study, the female:male ratio was $2: 1$ with female preponderance $84 \% .{ }^{[7]}$

Liang MK et al (2013), ${ }^{[8]}$ reported various contributing factors for development of incisional hernias. Strategies and surgical techniques were recognized which would reduce the frequency of, but will not reduce this problem.

Manninen MJ et al (1991), ${ }^{[9]}$ reported that obesity as the only factor clearly impairing the result of incisional hernioplasty-Good result were found in patients with normal weight $(87 \%)$ as compared to obese $(61 \%)$.

Post-operative pulmonary difficulties elevated the prevalence of herniation because of the stress placed on the wound closure by straining or coughing. Wound tensile stress was abnormal and ultimate wound stability is usually unsatisfactory in malnourished patients Baker. Et al $(1995),{ }^{[10]}$

Pain present in $26.66 \%$ patients in group A and $20 \%$ in group B at 1 month in our study. A similar results found by Roland W. Luijendijk et al (2000), ${ }^{[11]}$ the frequency of pain one month after surgery was similar in the two treatment groups (suture-repair group, 19 patients [20 percent]; meshrepair group, 15 patients [18 percent]). The pain usually disappeared after the first month.

Burger et al. reported post-operative pain by VAS in suture repair was 1.9 on average and 1.0 in mesh group $(\mathrm{p}=$ $0.04)$. $^{[12]}$

Venclauskas et al. ${ }^{[13]}$ reported that remarkably less pain after tension-free reconstruction in 1, 3, 6, and 12 month follow-up time ( $p<0.05$ in each follow-up).

Armstrong et al. ${ }^{[14]}$ found a markedly diminution in postoperative pain in patients who received a transverse incision compared to midline incision.

The recurrence of hernia was present in $28 \%$ cases in group A and $4 \%$ in group B. It was statistically significant $\left(\mathrm{P}=0.0488^{*}\right)$ at 3 months and the mostly were well built and have $27.27 \%$ wound infection present in these type of patients. Mostly infection occurred in obese patients (40\%). In techniques for the repair of incisional hernias in which sutures are used, the edges of the defect are brought together, which may lead to excessive tension and 
subsequent wound dehiscence or incisional herniation as a result of tissue ischemia and the cutting of sutures through the tissues. ${ }^{[15]}$ With prosthetic mesh, defects of any size can be repaired without tension. In addition, polypropylene mesh, by inducing an inflammatory response, sets up a scaffolding that, in turn, induces the synthesis of collagen. Our study establishes the superiority of mesh repair over suture repair with regard to the recurrence of hernia. The recurrence rate in suture repair group in our study is comparable to Korenkov et al. ${ }^{[16]}$ series. Another study showed that the matapurkar (1995), ${ }^{[17]}$ showed $0 \%$ recurrence rate in mesh repair.

\section{Conclusion}

We concluded that restoration with polypropylene mesh is superior to suture repair group with concern to the recurrence of hernia. According to our knowledge in case of incisional hernias the onlay reconstruction is an alternative option that provides satisfactory low rate of recurrence.

\section{References}

1. Sorensen LT, Jorgensen LN, Gottrup F. Biochemical aspects of abdominal wasll hernia formation and recurrence. In; Firzgibbons R, Greenberg G, (eds). Nyhus and condons Hernia, 5th Ed. Philadelphia USAL Lippincott Williams and Wilkins; 2002. P.14

2. Lichtenstein IL, Shulman AG, Amid PK, Montllor MM. The tensionfree hernioplasty. Am J Surg. 1989;157(2):188-93.

3. Arshad M Malik, Asad Khan, AtifJawaid, Abdul Aziz Laghari, K. AltafHussainTalpur. A comparative analysis b/w non mesh (Bassini's) and mesh (Lichtenstein) repair of primary inguinal hernia J Ayub Med Coll Abbottabad 2009;21(1):17-20.
4. Shell DH, de la Torre J, Andrades P, Vasconez LO. Open Repair of Ventral Incisional Hernias. SurgClin North Am.2008; 88(1): 61-83.

5. Millikan KW. Incisional hernia repair. SurgClin North Am.2003; 83(5): 1223-34.

6. Michael Zinner, Seymour I. Schwartz,Harold Ellis. Maingot's: Abdominal operations. 10th ed; Vol. 1:423-425 and 548-72.

7. Bhutia WT, Chandra SS, Srinivasan K, Ananthakrishna N. Factors predisposing to incisional hernia after laparotomy and influencing recurrences rate after different methods of repair: A prospective study of 220 patients. IJS.1993;55 (11): 535-43.

8. Liang MK, Berger RL, Li LT, Davila JA, Hicks SC, Kao LS.Outcomes of Laparoscopic vs Open Repair of Primary Ventral Hernias. JAMA Surg. 2013;148(11):1043-8.

9. Manninen MJ, Lavonius M and Perhoniemi VJ. Results of incisional hernia repair. A retrospective study of 172 unselected hernioplasties.Eur J Surg. 1991 Jan;157(1):29-31.

10. Baker RJ. Incisional hernias. In: Nyhus LM, Condon RE, editors. Hernia. 3rd ed. Philiadelphia, Pennsylvania: Lippincott; 1995: 319-36.

11. Luijendijk RW, Hop WC, van den Tol MP, de Lange DC, Braaksma $\mathrm{MM}$, et al. A comparison of suture repair with mesh repair for incisional hernia. N Engl J Med. 2000;343(6): 392-8.

12. Burger JWA, Luijendijk RW, Hop WCJ, Halm JA, Verdaasdonk EGG, et al. Long-term Follow-up of a Randomized Controlled Trial of Suture Versus Mesh Repair of Incisional Hernia. Ann Surg. 2004; 240(4): 578-85.

13. Venclauskas L, Silanskaite J, Kanisauskaite J, Kiudelis M. Long-term results of incisional hernia treatment. Medicina (Kaunas).2007; 43: 855-60.

14. Armstrong PJ, Burgess RW. Choice of incision and pain following gallbladder surgery. Br J Surg.1990; 77(7): 746-8.

15. George CD, Ellis $\mathrm{H}$. The results of incisional hernia repair: a twelve year review. Ann R Coll Surg Engl. 1986;68(4):185-7

16. Korenkov M, Sauerland S, Arndt M, Bograd L, Neugebauer EA, Troidl H. Randomized clinical trial of suture repair, polypropylene mesh or autodermalhernioplasty for incisional hernia. Br J Surg. 2002;89(1):50-6.

17. Matapurkar B. Large recurrent incisional hernia: Ultra sonographic mapping of abdominal wall defects and repair by Marlex peritoneal sandwich technique. Indian J Surg. 1995;321-5.

Copyright: () the author(s), 2020. It is an open-access article distributed under the terms of the Creative Commons Attribution License (CC BY 4.0), which permits authors to retain ownership of the copyright for their content, and allow anyone to download, reuse, reprint, modify, distribute and/or copy the content as long as the original authors and source are cited.

How to cite this article: Jeengar VK, Verma R. A Prospective Study to Evaluate the Effectiveness of Prolene Mesh Repair in Incisional Hernia: A Hospital Based Study.Asian J. Med. Res. 2020;9(1):PT09-PT11.

DOI: dx.doi.org/10.47009/ajmr.2020.9.1.PT3

Source of Support: Nil, Conflict of Interest: None declared. 